\title{
Changing urban forms and carbon dioxide emissions in China: A case study of 30 provincial capital cities
}

\author{
Chuanglin Fang ${ }^{\mathrm{a}}$, Shaojian Wang ${ }^{\mathrm{b}, *}$, Guangdong $\mathrm{Li}^{\mathrm{a}, *}$ \\ a Institute of Geographic Sciences and Natural Resources Research, Chinese Academy of Sciences, Beijing 100101, China \\ ${ }^{\mathrm{b}}$ School of Geography and Planning, Sun Yat-sen University, Guangzhou 510275, China
}

\section{H I G H L I G H T S}

- The relationship between urban form and $\mathrm{CO}_{2}$ emissions is investigated.

- A panel data model is used, taking the period 1990-2010.

- The growth of urban areas correlates positively with $\mathrm{CO}_{2}$ emissions.

- Increases in urban continuity has an inhibitory effect on $\mathrm{CO}_{2}$ emissions.

- Increased urban shape complexity exhibits a positive influence in relation to $\mathrm{CO}_{2}$ emissions.

\section{A R T I C L E I N F O}

\section{Article history:}

Received 15 December 2014

Received in revised form 19 August 2015

Accepted 21 August 2015

Available online 5 September 2015

\section{Keywords:}

Urban form

$\mathrm{CO}_{2}$ emissions

Panel data model

30 Provincial capital cities

China

\begin{abstract}
A B S T R A C T
Urban form is increasingly being recognised by scientists for the potential role it might play in the coordination of sustainable urban development and the reduction of $\mathrm{CO}_{2}$ emissions. However, despite increasing interest in the morphology of cities in climate change science, few quantitative estimates have been made of the effects of urban form on $\mathrm{CO}_{2}$ emissions. The goal of this study is to quantify this relation, using panel data for China's 30 provincial capital cities from 1990 to 2010. In order to meet this aim, we first selected a series of urban form indicators, which we quantified by applying spatial metrics to remotely sensed data. We then estimated $\mathrm{CO}_{2}$ emission levels using a unified standard method recommended by the IPCC Guidelines, and subsequently performed a panel data analysis. The results of the study demonstrated a positive correlation between the growth of urban areas and $\mathrm{CO}_{2}$ emission levels. Further, it was also found that increased "urban continuity" led to reductions in $\mathrm{CO}_{2}$ emissions and that, conversely, increased "urban shape complexity" exerted a positive influence in relation to $\mathrm{CO}_{2}$ emissions. The findings of this study indicate that measures to make existing cities in China more compact may in fact help to reduce levels of $\mathrm{CO}_{2}$ emissions, just as increasing fragmentation or increased irregularity with respect to urban form may contribute to increased $\mathrm{CO}_{2}$ emissions. If serious about achieving meaningful reductions in $\mathrm{CO}_{2}$ emissions, decision makers and planners should take urban form into consideration when developing low-carbon cities in China.
\end{abstract}

(ㄷ) 2015 Elsevier Ltd. All rights reserved.

\section{Introduction}

Carbon dioxide $\left(\mathrm{CO}_{2}\right)$ is the greatest known contributor to climate change, and the global warming we are currently witnessing

\footnotetext{
Abbreviations: $C E, \mathrm{CO}_{2}$ emissions; $E$, fossil fuels; $F, \mathrm{CO}_{2}$ emissions coefficient; $T A$ total area; LPI, largest patch index; AWMSI, area weighted mean shape index; AWMPFD, area weighted mean patch fractal dimension; PARA_MN, mean perimeter area ratio; PLADJ, percentage of like adjacencies; COHESION, patch cohesion index; $A I$, aggregation index; $L S I$, landscape shape index; CONTIG, contiguity.

* Corresponding authors. Tel./fax: +86 02084111963 (S. Wang), +86 010 64889101 (G. Li).

E-mail addresses: 1987wangshaojian@163.com (S. Wang), ligd@igsnrr.ac.cn (G.
}

is a result of rising $\mathrm{CO}_{2}$ levels in the Earth's atmosphere [1]. Human emissions of the gas, which have been increasing globally since at least the Industrial Revolution (that is, the late 18th century), have now reached levels not seen for at least three million years [2]. Concomitantly, the past century has also seen the gradual transition of the global population towards urban living, a shift which has resulted in spectacular levels of urbanisation, with the global urbanisation level rising from $10 \%$ in 1900 to $52.6 \%$ in $2011[3,4]$. Linking these two developments, current scientific research indicates that human activities in urban areas now constitute the primary source of anthropogenic $\mathrm{CO}_{2}$ emissions [4], and cities, whilst covering less than 3\% of the Earth's surface, consume $75 \%$ of the 
world's energy and produce $80 \%$ of global greenhouse gas emissions [5]. At the same time, cities and towns can also promote global economic growth and improve living standards. Whilst city administrations and national governments struggle to support economic development, they therefore also face increasing pressure to address the impacts of climate change associated with such growth. Curbing fossil-energy use and emissions in urban areas while concurrently continuing to maintain urban development therefore constitutes a key challenge for governments internationally [6-9]. In the context of this complex issue, decision makers and urban planners concerned with sustainable development are required to pay great attention to the formulation of measures that can effectively reduce $\mathrm{CO}_{2}$ emissions and mitigate climate change. In addition to traditional emission reduction measures that rely on technology and policy solutions, it is recognised that urban form (that is, the spatial patterns and structural features of urban land use) is implicated in urban $\mathrm{CO}_{2}$ emission levels $[9,10]$. Despite this recognition, only a limited number of studies have empirically evaluated the direct impacts of different urban form patterns on $\mathrm{CO}_{2}$ emissions. This deficiency in the current research motivates the present study and its aim to quantify the relationship between urban form and $\mathrm{CO}_{2}$ emissions.

Although many factors affect $\mathrm{CO}_{2}$ emissions (for instance, industrial production, transportation, local climates and the burning of fossil fuels, to name but a few), the spatial evolution of urban sprawl is highlighted as a particularly important influencing factor [11-15]. Urban form can be defined as the spatial organisation and arrangement of human activities - it affects how cities grow and expand and how efficiently they are able to configure resources, land use, transport and infrastructure $[10,12,16]$. Previous studies have addressed a number of influencing factors which begin to explain the relation between urban form and $\mathrm{CO}_{2}$ emissions $[12,17-22]$, particularly in terms of the effects of urban form on urban infrastructure [23], urban transportation [24], urban heat inland effects [25], carbon taxes [26], the energy efficiency of buildings [11] and residential energy demand [27], in addition to local climatic conditions. Pursuant to these previous studies, the impact of urban form on $\mathrm{CO}_{2}$ emissions appears to be both significant and profound. Taking this link as the basis for their work, a number of scholars have concluded that designing more compact and more complex cities could decrease $\mathrm{CO}_{2}$ emissions. For instance, using Helsinki city as an example, Harmaajarvi et al. [28] found that a compact urban development pattern could save as much as $35 \%$ of the study district's 2010 total energy usage, through changes in urban transport and district heating. In their analysis of the relationship between the urban form patterns of China's fastest growing cities and $\mathrm{CO}_{2}$ emissions, which used panel data analysis, Ou et al. [10] similarly found that compact, multiplenuclei development patterns (rather than dispersed, single-nuclei development patterns) help to reduce $\mathrm{CO}_{2}$ emissions. These results are supported by the findings of studies undertaken in relation to the U.K. by Banister [29], in Canada by Christen et al. [30], in Japan by Makidoa et al. [31] and in China by Wang et al. [22]. Using Beijing as an example, Ma et al. [32] investigated how urban form impact individual's daily travel behaviour and subsequent $\mathrm{CO}_{2}$ emission from work and non-work trips, respectively. They found that residents living in neighbourhoods with higher job density emitted less $\mathrm{CO}_{2}$ from work related trips, and people resident in neighbourhoods with higher retail density tended to travel shorter distance and emitted less $\mathrm{CO}_{2}$ emission from non-work trips. From the viewpoint of energy consumption and $\mathrm{CO}_{2}$ emissions to assess the sustainability of urban form, Ye et al. [33] found that urban sprawl aspects of compactness were positively correlated with urban household energy use $\mathrm{CO}_{2}$ emissions. Using 125 largest urbanised areas in the U.S., Lee and Lee [34] examined how urban form influence an individual household's $\mathrm{CO}_{2}$ emissions. They found that doubling population-weighted density was associated with a reduction in $\mathrm{CO}_{2}$ emissions from household travel and residential energy consumption by $48 \%$ and $35 \%$, respectively. They suggested that smart growth policies to build more compact cities were useful to mitigate $\mathrm{CO}_{2}$ emissions. Similarly, using the Greater Dublin Region as an example, Liu and Sweeney [27] estimated the relationship between $\mathrm{CO}_{2}$ emissions and urban form. They found that the energy-related $\mathrm{CO}_{2}$ emissions could be significantly decreased by building compact cities.

These existing studies generally indicate that low-carbon energy solutions and energy conservation are important emission reduction measures. However, urban planning and spatial optimisation methods are also required to reduce $\mathrm{CO}_{2}$ emissions [2]. Studies addressing the nature of the link between urban form and $\mathrm{CO}_{2}$ emissions have, as a result, become increasingly important. As a factor associated with spatial urban planning, urban form could in fact constitute the basis for a new rationale in the coordination of urban sustainable development and the reduction of $\mathrm{CO}_{2}$ emissions. It is therefore quite remarkable that such a limited number of studies have engaged in the task of quantitatively estimating spatiotemporal changes in urban form, or have quantified the impact of urban growth and sprawl on $\mathrm{CO}_{2}$ emissions. Although some studies have attempted to quantify urban form patterns by calculating ratios between two related variables (for instance, through the use of compactness ratios, elongation ratios and urban population density measures) [21], such research denies the process-based character of urban sprawl - which in fact evolves spatially - and further, it neglects the fundamental role played by the basic statistical unit (in terms of landscape metrics). These omissions are evident in the study of $\mathrm{CO}_{2}$ emissions in Beijing conducted by Qin and Shao [35], who, whilst presenting a new method based on questionnaire data in relation to building and travel (a method which enabled them to estimate the direct $\mathrm{CO}_{2}$ emissions of the residents of a given community), did not consider the land-use patterns and characteristics of their study area. Although previous studies have certainly enriched our understanding of the relationships between $\mathrm{CO}_{2}$ emissions and urban form, they have concurrently failed to provide systematic and explicit evidence in relation to how urban form affects those emissions.

The design of the present study attempts to address many of these deficiencies. As such, we first calculated energy-related $\mathrm{CO}_{2}$ emissions using a unified standard method recommended by the IPCC Guidelines [36]. We then analysed and compared the urban form patterns of various cities using pre-existing sprawl indexes and spatial metrics based on remotely sensed land-use and landcover data. Based on these calculations, and by employing a range of analysis techniques, we generated a number of quantitative measures in relation to the spatial and temporal characteristics of $\mathrm{CO}_{2}$ emissions, of urban built-up areas and of various urban form patterns. Finally, we attempted to quantify the relationship between $\mathrm{CO}_{2}$ emissions and urban form using a panel data analysis. The panel data model was chosen because of its many advantages over conventional cross-sectional or time series models $[37,38]$. China's 30 provincial capital cities (Beijing, Changchun, Changsha, Chengdu, Chongqing, Fuzhou, Guangzhou, Guiyang, Harbin, Haikou, Hangzhou, Hefei, Hohhot, Jinan, Kunming, Lanzhou, Nanchang, Nanjing, Nanning, Shanghai, Shenyang, Shijiazhuang, Taiyuan, Tianjin, Wuhan, Urumqi, Xi'an, Xining, Yinchuan, and Zhengzhou) constituted the study area in this research. As provincial capital cities, these cities suffer from a series of environmental problems and their $\mathrm{CO}_{2}$ emissions continue to grow as a result of their rapid urban growth and sprawl. Addressing the panel of these 30 cities, the study attempted to explore the relationships between urban form and $\mathrm{CO}_{2}$ emissions using time series data for the period 1990-2010. Our findings not only offer a scientific model for analysis, but also suggest a rational path 
for future urban expansion strategies, thereby providing guidance for the formulation of future urban planning principles.

The remainder of this paper is organised as follows. Section 2 briefly describes the study area. Section 3 focuses on methodology and data, presenting the methods used to estimate $\mathrm{CO}_{2}$ emissions and urban form aspects, the parameter estimation of the econometric model and the data used within the study. Results and discussion are given in Section 4, and the conclusions and policy implications of the study are summarised in Section 5.

\section{Study area}

As sites for rapid urban development and for sprawl, built-up areas were considered the most suitable objects of study for estimating the relationship between urban form and $\mathrm{CO}_{2}$ emissions. As such, China's 30 provincial capital cities (that is, all of China's provincial cities except Lhasa, an exclusion that was performed due to limited data), which constitute the fastest growing areas in their respective provinces, were selected to constitute the study area. Their spatial distributions are shown in Fig. 1. These cities both maintain a number of similarities and deviate strongly from each other. On the one hand, they each have long histories of urban development, large populations and high GDPs. On the other, they significant differences exist in their urban spatial patterns and $\mathrm{CO}_{2}$ emissions trends. These differences reflect their different population densities and locations, as well as the impact of different economic scales and development policies. As China's leading powerhouses in the past two decades, the 30 Chinese provincial capitals are considered representative of the rapid growth witnessed in urban China.

As the most rapidly growing cities in China, the cities which comprise the study area all suffer from different levels of environmental pressure, and their $\mathrm{CO}_{2}$ emissions continue to grow due to the rapid development of their economies, which in turn has also demanded vast volumes of natural resources. Despite the fact that urban development can lead to increases in the incomes of residents and to the improvement of people's living standards, it must also be acknowledged that such growth can also lead to increases in energy consumption and consequently bring about a number of environmental problems $[9,10]$. This becomes particularly clear when one considers that the total urban built-up area in the 30 cities, which was approximately $4314.54 \mathrm{~km}^{2}$ in 1990 , measured over $8429.14 \mathrm{~km}^{2}$ in 2010 , an increase which has not only led to the conversion of natural ecosystems, farmland and water into urban area, but has also resulted in many environmental changes, leading to increased global warming and the urban heat island effect $[10,39]$. Thus, on the path towards developing low-carbon cities through the realisation of $\mathrm{CO}_{2}$ emission intensity targets for mitigating climate change effects, it is necessary to identify the important influencing factors which lie behind the production of $\mathrm{CO}_{2}$ emissions in fast-growing cities [6]. In addition, a better understanding of this relationship is also required in order to enable policy makers and urban planners to curb $\mathrm{CO}_{2}$ emissions while fostering sustainable urban development. The quantification of the relationship between urban form and $\mathrm{CO}_{2}$ emissions in the 30 Chinese provincial capitals which constitute the study area for this research is hoped to contribute to the development of precisely such an understanding.

\section{Materials and methods}

\subsection{Estimating energy-related $\mathrm{CO}_{2}$ emissions}

Due to the lack of city-level anthropogenic $\mathrm{CO}_{2}$ emissions statistics in China, it is difficult to acquire precise data officially. Previous studies have conclusively demonstrated that human activities such

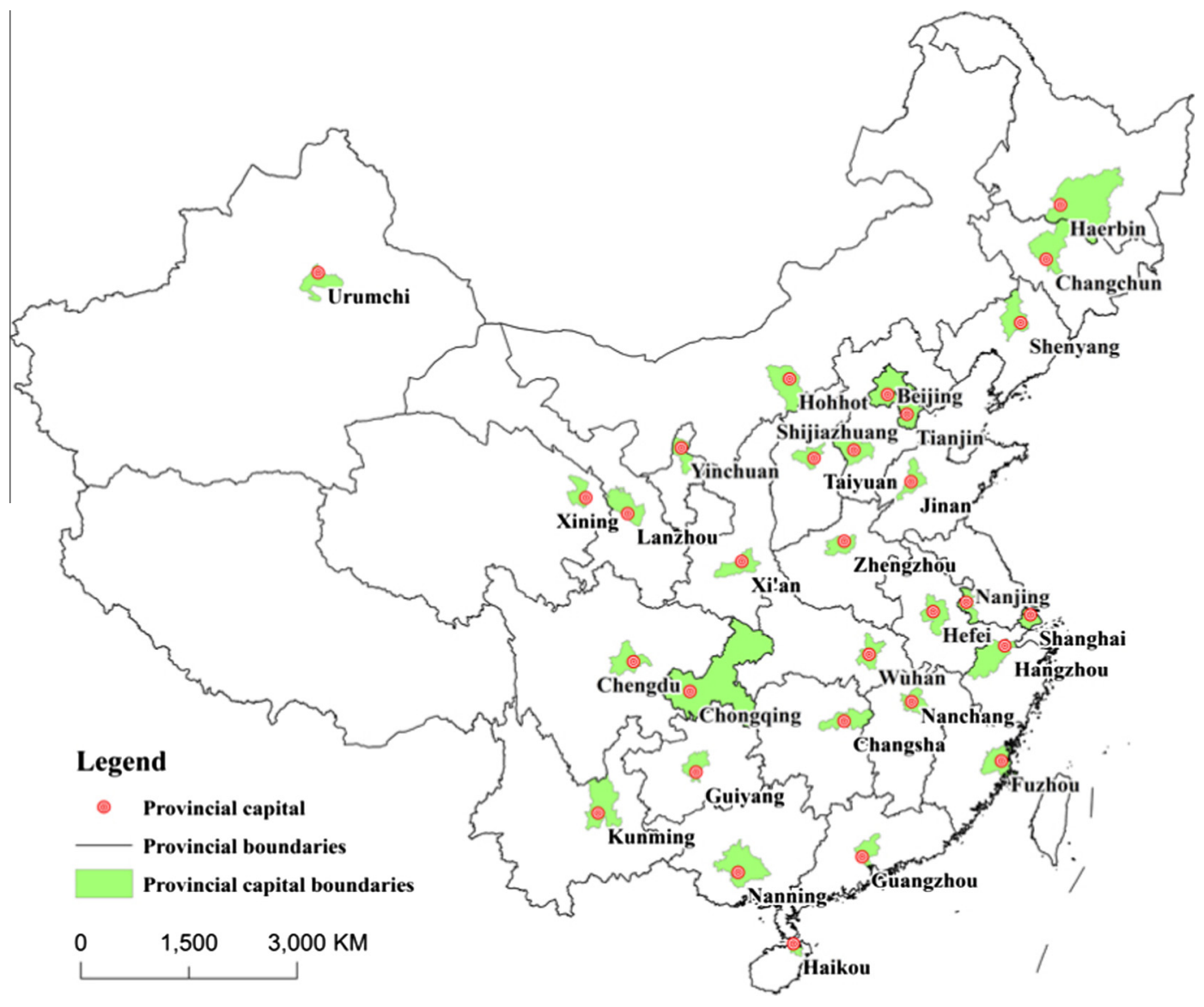

Fig. 1. Spatial distributions of 30 Chinese provincial capital cities in China. 
Table 1

Calorific value and $\mathrm{CO}_{2}$ emission coefficients of fuel types.

\begin{tabular}{lll}
\hline Type of fossil energy & $\begin{array}{l}\text { Low calorific value of } \\
\text { energy }\end{array}$ & $\begin{array}{l}\mathrm{CO}_{2} \text { emissions } \\
\text { coefficient }\end{array}$ \\
\hline Coal & $20,934 \mathrm{~kJ} / \mathrm{kg}$ & $94,600 \mathrm{~kg} / \mathrm{TJ}$ \\
Coke & $28,470 \mathrm{~kJ} / \mathrm{kg}$ & $107,000 \mathrm{~kg} / \mathrm{TJ}$ \\
Crude oil & $41,868 \mathrm{~kJ} / \mathrm{kg}$ & $73,300 \mathrm{~kg} / \mathrm{TJ}$ \\
Fuel oil & $41,868 \mathrm{~kJ} / \mathrm{kg}$ & $77,400 \mathrm{~kg} / \mathrm{TJ}$ \\
Gasoline & $43,124 \mathrm{~kJ} / \mathrm{kg}$ & $70,000 \mathrm{~kg} / \mathrm{TJ}$ \\
Coke oven gas & $17,375 \mathrm{~kJ} / \mathrm{cu} \mathrm{m}$ & $44,366 \mathrm{~kg} / \mathrm{TJ}$ \\
Kerosene & $43,124 \mathrm{~kJ} / \mathrm{kg}$ & $71,900 \mathrm{~kg} / \mathrm{TJ}$ \\
Diesel oil & $42,705 \mathrm{~kJ} / \mathrm{kg}$ & $74,100 \mathrm{~kg} / \mathrm{TJ}$ \\
Liquefied petroleum & $50,241 \mathrm{~kJ} / \mathrm{kg}$ & $63,100 \mathrm{~kg} / \mathrm{TJ}$ \\
$\quad$ gas & $38,979 \mathrm{~kJ} / \mathrm{cu} \mathrm{m}$ & $56,100 \mathrm{~kg} / \mathrm{TJ}$ \\
Natural gas & - & $10,069(\mathrm{t} / \mathrm{B} \mathrm{kW} \mathrm{h})$ \\
Electricity & &
\end{tabular}

as the burning of fossil fuels and deforestation are the primary cause of the increased $\mathrm{CO}_{2}$ concentrations in the atmosphere; in fact, $87 \%$ of all human-produced $\mathrm{CO}_{2}$ emissions have been shown to come from the consumption of fossil fuels like coal, natural gas and oil [40]. As such, the use of energy-related statistical data offers a useful method to estimate emissions and thereby obtain approximate $\mathrm{CO}_{2}$ emissions data $[9,10,40,41]$. Using the coefficients published by the IPCC [36], the calculation of energyrelated $\mathrm{CO}_{2}$ emissions can be undertaken on the basis of the following formula:

$C E_{i t}=\sum E_{i j t} \times F_{j} \times \alpha_{j}$

where $C E_{i t}$ represents the energy-related $\mathrm{CO}_{2}$ emissions of the $i$-th city in the $t$-th year; $E_{i j t}$ denotes the $j$-th fossil fuels of the $i$-th city in the $t$-th year; $F_{j}$ is the $\mathrm{CO}_{2}$ emissions coefficient of $j$-th fossil fuels
(Table 1 ); and $\alpha_{j}$ is the low calorific value of $j$-th fossil fuels (Table 1 ). According to the energy balance tables derived from the China Energy Statistical Yearbook, fossil energy is subdivided into ten categories: coal, coke, crude oil, fuel oil, gasoline, kerosene, diesel oil, liquefied petroleum gas, natural gas and electricity. Unfortunately, limited data are available for these categories at the scale of urban built-up areas. Rather than using the built-up area scale, fossil energy use data was extracted from China City Statistical Yearbook (1991, 2001 and 2011) at the municipal district scale. Municipal districts, which are administrative units used in the China City Statistical Yearbook and which typically cover built-up areas and their urban fringes, offer an alternative scale for data collection [42]. Because of different rule-based statistical methods used between the 1990s, the 2000s and the 2010s, the ten categories of energy consumption could not be identified completely [43]. Under such circumstances, the only alternative method for calculating $C_{i t}$ is through analysis of existing data and by making estimations where necessary [44]. In this study, $C$ includes the consumption of coal, gas, electricity, and liquefied petroleum gas. Both the low calorific value and $\mathrm{CO}_{2}$ emissions coefficient of each fuel type were collected from the IPCC Guidelines [36].

\subsection{Urban forms}

In order to characterise the spatial and temporal dynamics of the urban form of each of China's 30 provincial capital cities, we used Landsat Thematic Mapper (TM) and Enhanced Thematic Mapper (ETM) to identify the boundaries of urban built-up areas ("urban built-up area" in this paper refers to the fully developed area of a central city and its suburbs that includes no rural land [44]) for three time periods: 1990, 2000 and 2010, at a mapping scale of

Table 2

Remote sensing imagery data sources for extraction of urban built-up area.

\begin{tabular}{|c|c|c|c|}
\hline Cities & 1990 & 2000 & 2010 \\
\hline Beijing & P123R032_5X19920907 & P123R032_7X19990701 & L512303220090922 \\
\hline \multirow[t]{2}{*}{ Shanghai } & P118R038_5DT19890811 & P118R038_7DT20010703 & L511803820090919 \\
\hline & P118R039_5X19870518 & P118R039_7X20000614 & L511803920090717 \\
\hline Tianjin & P122R033_5X19930615 & P122R033_7X20010901 & LT51220332009242 \\
\hline \multirow[t]{2}{*}{ Chongqing } & P127R040_5X19880604 & P128R039_7X20010522 & LT51280402010223 \\
\hline & P128R039_5X19880915 & P128R040_7X20010522 & LT51280392010143 \\
\hline Shijiazhuang & P124R034_5X19931019 & P124R034_7X20000507 & LT51240342010227 \\
\hline Taiyuan & P125R034_5X19900916 & P125R034_7X20000701 & LT51250342010266 \\
\hline Hohhot & P126R032_5X19870915 & P126R032_7X20020714 & LT51260322009222 \\
\hline Shenyang & P119R031_5X19921013 & P119R031_7X20010811 & LT51190312010224 \\
\hline Changchun & P118R030_5X19930907 & P118R030_7X2000102 & LT51180302010153 \\
\hline Haerbin & P118R028_5X19890912 & P118R028_7X20010921 & LT51180282010265 \\
\hline Nanjing & P120R038_5DT19880705 & P120R038_7DT20011106 & L512003820100819 \\
\hline Hangzhou & P119R039_5X19910723 & P119R039_7X20001011 & LE71190392010264 \\
\hline Hefei & P121R038_5X19900920 & P121R038_7X20011012 & LT51210382009123 \\
\hline Fuzhou & P119R042_5X19890615 & P119R042_7X20010304 & LT51190422009157 \\
\hline Nanchang & P121R040_5X19890715 & P121R040_7X20000923 & LE71210402010278 \\
\hline Jinan & P122R035_5X19870919 & P122R035_7X20020531 & LT51220352009242 \\
\hline Zhengzhou & P124R036_5DT19880514 & P124R036_7DT20010510 & L512403620090625 \\
\hline Wuhan & P123R039_5X19910719 & P123R039_7X20020709 & LT51230392009249 \\
\hline \multirow[t]{2}{*}{ Changsha } & P123R040_5X19931012 & P123R041_7X20011229 & LT51230402009249 \\
\hline & P123R041_5X19930825 & P123R040_7X20010924 & LT51230412009233 \\
\hline Guangzhou & P122R044_5X19901013 & P122R044_7X20000914 & LT51220442009306 \\
\hline Nanning & P125R044_5X19900916 & P125R044_7X20001224 & LT51250442009279 \\
\hline Haikou & P124R046_5X19911030 & P124R046_7X20010729 & LT51240462010083 \\
\hline Chengdu & P129R039_5X19920816 & P129R039_7X20001102 & LT51290392009083 \\
\hline Guiyang & P127R042_5X19931227 & P127R042_7X20011123 & LE71270422010304 \\
\hline Kunming & P129R043_5DT19920816 & P129R043_7DT20001102 & L7112904320091111 \\
\hline Xi'an & P127R036_5X19880823 & P127R036_7X20020603 & LT51270362009181 \\
\hline Lanzhou & P130R035_5X19930826 & P130R035_7X19990718 & LT51300352009218 \\
\hline Xining & P132R035_5X19960816 & P132R035_7X19990801 & LE71320352010211 \\
\hline Yinchuan & P129R033_5DT19910830 & P129R033_7DT19990812 & L7112903320100911 \\
\hline Urumchi & P142R030_5X19901009 & P142R030_7X19990823 & LT51420302009206 \\
\hline
\end{tabular}

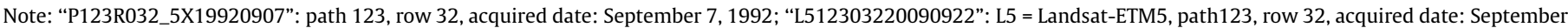
22, 1992. 
1:100,000. A total of 99 Landsat TM and ETM imageries (acquired by Global Land Survey 1990, 2000 and 2010) were applied to extraction of urban built-up area, including 33 scenes from Landsat TM for 1990, 33 scenes from Landsat TM for 2000 and 33 scenes from Landsat-ETM5/ETM7 for 2010. Table 2 shows a detailed summary of our data sources.

Using the above-mentioned remote sensing imagery database, we developed an urban built-up area database for China's provincial capital cities at a spatial scale of $1: 100,000$, using visual interpretation and vectorisation [45] with technical support from ENVI/ IDL 5.1 software and ArcGIS 10.1 (ERSI) software. A detailed workflow of imagery processing and urban built-up area boundary extractions is shown in Fig. 2. Before engaging in interpretation, a band composition was implemented in relation to the remotely sensed images. These images were then geo-referenced using 1:50,000 relief maps. For each TM/ETM scene, at least 20 evenly distributed sites, selected on the basis of a calibrated image and relief map, served as Ground Control Points (GCPs), which were applied in order to correct the image. The Root Mean Squared Error (RMS error) of geometric rectification was less than 1.5 pixels (or $45 \mathrm{~m}$ ) [45]. We then used ArcGIS10.1 software in order to identify the urban built-up area on the computer screen, based on our understanding of urban spectral reflectance, structure and other information. Boundaries were then drawn around the urban built-up areas, and a polygon attribute was added to these in order to produce the digital map. Finally, we edited and compiled the vector digital maps and implemented strict quality control. Fig. 3 details the footprints of urban expansion (obtained by using above methods) of five representative cities in different parts of China.

Urban form can affect economic functions and efficiency and bring about social impacts in the urban environment, ultimately affecting both the design and regulation of the uses of urban space. Based on previous studies [46-53], we selected ten pattern metrics to characterise urban form changes: total area (TA), the largest patch index (LPI), the area-weighted mean shape index (AWMSI), the area-weighted mean patch fractal dimension index (AWMPFDI), perimeter area ratio distribution (PARA_MN), the percentage of like adjacencies (PLADJ), the patch cohesion index (COHESION), the aggregation index (AI), the landscape shape index (LSI) and contiguity (CONTIG). TA equals the sum of urban built-up areas of all patches of the corresponding patch type; this metric helps to reveal the process of sprawl in a given urban built-up area. The LPI indicator equals the area of the largest patch of the corresponding patch type divided by the total landscape area, and represents the degree of urban dominance in the landscape [54]. The AWMSI is a robust metric used to describe landscape structure across spatial scales by calculating the complexity of urban patches according to their size [55]. The AWMPFDI measures the degree of irregularity of urban patch shapes, which implies the presence of unplanned growth in a given urban area [55]. The higher the fractal dimension index, the more irregular the shape of the urban area. PARA_MN is a simple measure of shape complexity. The PLADJ is an absolute measure of the aggregation of an urban landscape. COHESION measures the physical connectedness of the urban land patch. Patch cohesion increases as the patch type becomes more clumped or aggregated in its distribution and hence more physically connected. The AI is computed simply as an area-weighted mean class aggregation index. The LSI measures the perimeter-to area ratio for the landscape. CONTIG indicates the spatial aggregation of urban patches. Ten spatial pattern metrics were calculated using FRAGSTATAS 4.2 [56]. To meet the needs of the calculation, all the vector data for the urban built-up areas were converted to

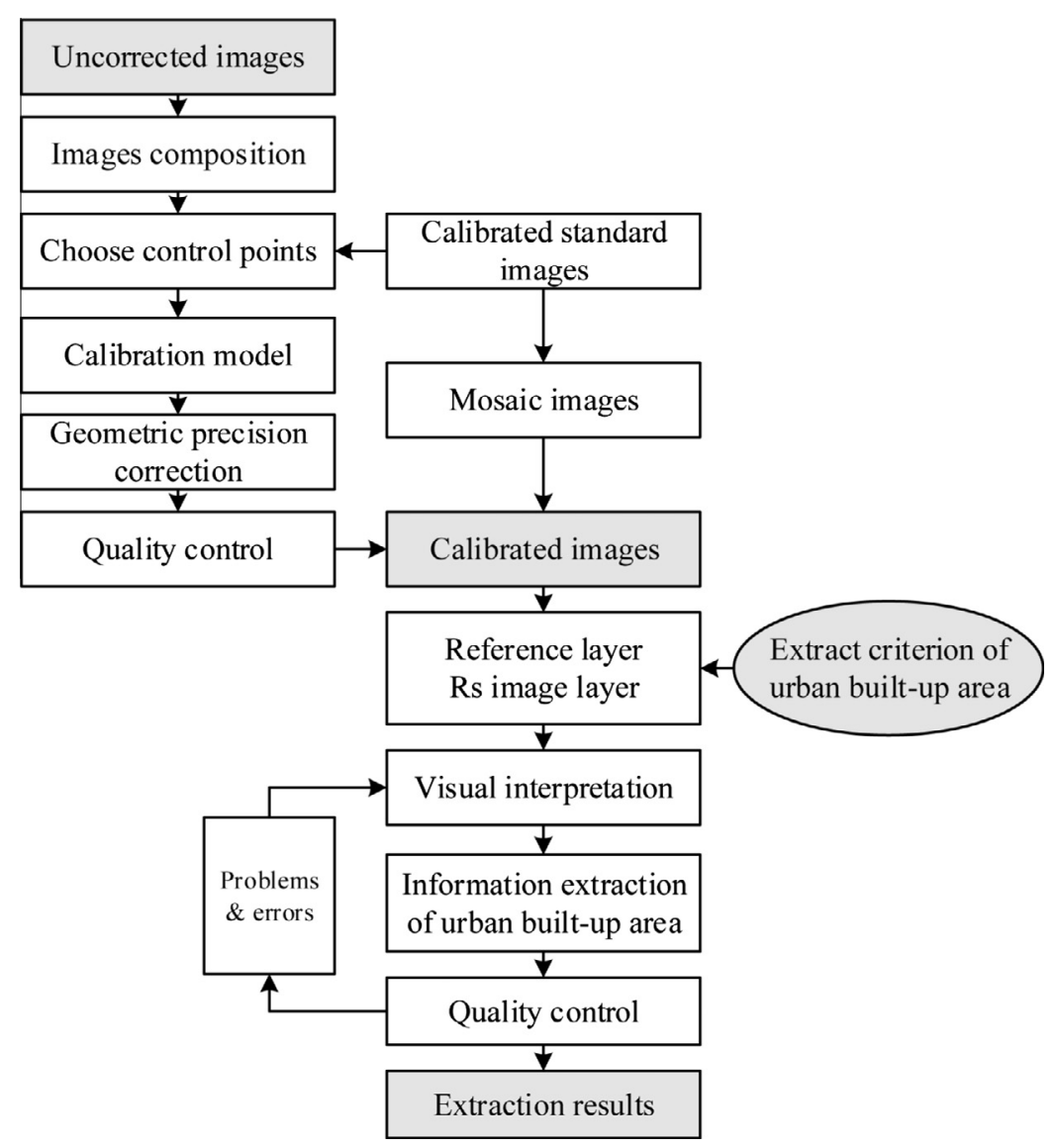

Fig. 2. The interpretation workflow of remote sensing imagery for extraction of urban built-up area. 

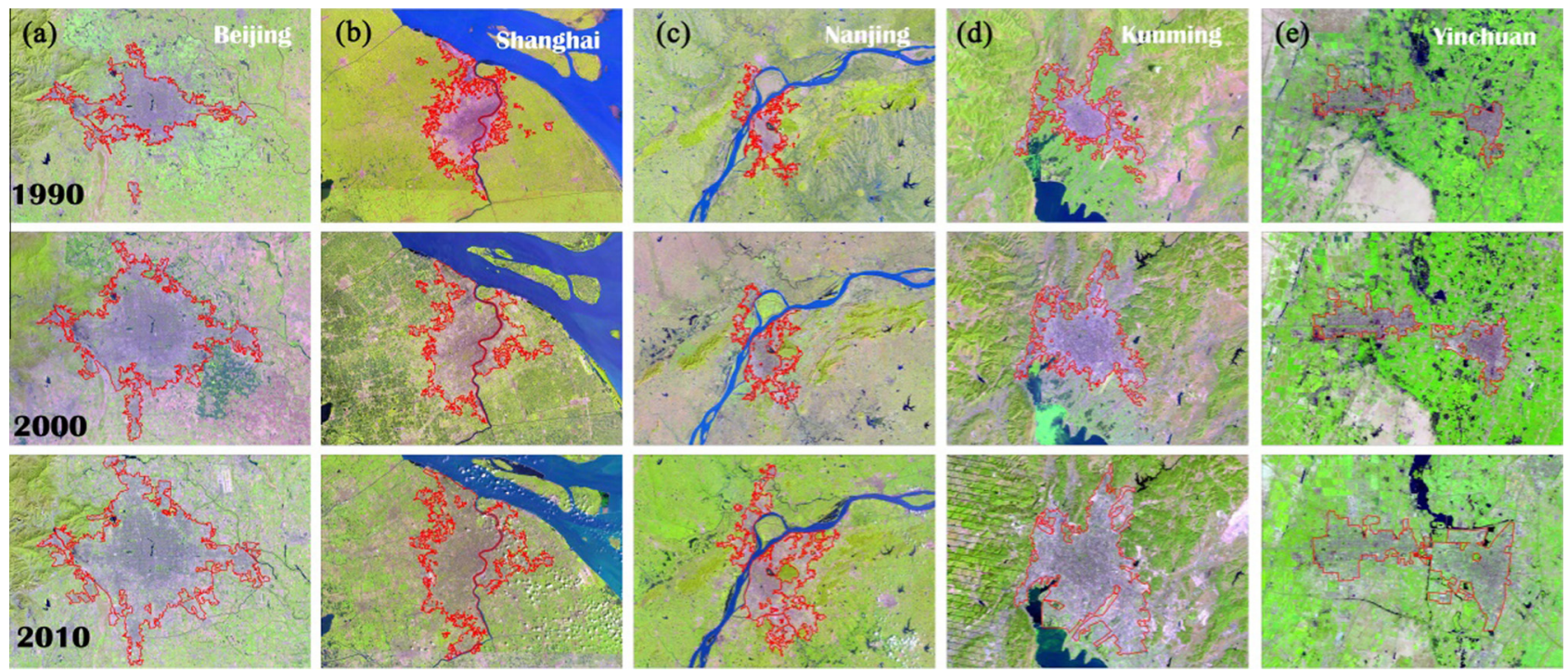

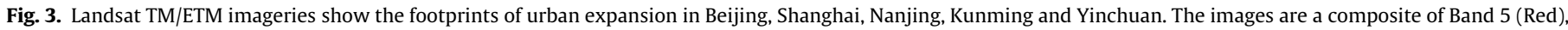

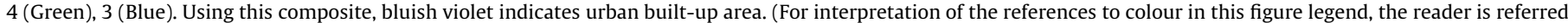
to the web version of this article.)

$30 \mathrm{~m} * 30 \mathrm{~m}$ raster data. Table 3 sets out a more detailed description of the above, including the specific mathematical equations of each of the metrics.

\subsection{Econometric models}

A panel data model, which took the period of 1990-2010 into consideration, was utilised in this study. The panel model was chosen because it has several major advantages over conventional cross-sectional or time series models $[37,38]$. For example, panel data usually has a high power to control individual heterogeneity. More importantly, it can help reduce the effects of multicollinearity among the variables and increase the degrees of freedom [37].

This study aimed to quantitatively estimate the relationship between urban form and $\mathrm{CO}_{2}$ emissions in 30 Chinese provincial capital cities, and as such a $\mathrm{CO}_{2}$ model needed to be built. The specific equation for that model was as follows:

$C E_{i t}=\beta_{i}+\mathbf{Z}_{\mathbf{i t}} \boldsymbol{\varphi}+\mu_{i}+\varepsilon_{i t}$

where $C E_{i t}$ is the $\mathrm{CO}_{2}$ emissions of city $i$ in year $t$; $\beta_{i}$ is a scalar coefficient; $\varphi$ is a vector of parameters; $\mu_{i}$ denotes the individual effect, capturing the idiosyncratic characters of each city; $\varepsilon_{i t}$ denotes the random error; and $\mathbf{Z}_{\mathbf{i t}}$ is a vector of exogenous variables, including TA, LPI, AWMSI, AWMPFD, PARA_MN, PLADJ, COHESION, AI, LSI and CONTIG. All data must undergo natural logarithm transformation to avoid non-stationarity and heteroskedasticity phenomena in the time series variables. Because Eq. (3) is a combination form, several specific regression models needed to be intensified through the inclusion of different exogenous variables [38]. Generally, if $T$ denotes the number of time points and $K$ represents the number of independent variables, the panel data model has to meet the requirement that $T>K+1$.

Before conducting the panel data model, we needed to decide whether the fixed effects or random effects model should be used. The fixed effects model is able to intensify the differences between individuals. Furthermore, it permits correlations between the exogenous variables $\mathbf{Z}_{\mathbf{i t}}$ and the individual specific effect $\mu_{i}$; however, it has relative small degrees of freedom resulting from its many scalar coefficients. The random effects model allows greater degrees of freedom, however its high power (when compared to the fixed effects estimator) is conditional on $\mathbf{Z}_{\mathbf{i t}}$ and $\mu_{i}$ having no correlated relationship. Whether the model would be accepted was based on the result of a Hausman test, a test which examines whether the covariance estimators of $\varphi$ are obviously different [57].

To solve the stationarity problem, the panel unit root test Levin, Lin and Chu (LLC) was utilised [58]. A panel unit root test was chosen on the basis of its higher power when compared to the normal time series and cross section data [38]. Generally, the LLC test is based on the following autoregressive model [37]:

$\Delta y_{i t}=\rho y_{i t-1}+\sum_{j=1}^{k_{t}} r_{j i} \Delta y_{i t-1}+\mathbf{Z}_{\mathbf{i t}} \boldsymbol{\varphi}+\varepsilon_{i t}$

where $\mathbf{Z}_{\mathbf{i t}}$ denotes the column vector of exogenous variables (deterministic variables); and $\varphi$ represents the column vector of regression coefficients. The alternative and the null hypothesis can be written as follows:

$$
\begin{aligned}
& \mathrm{H}_{1}: \rho<0 \\
& \mathrm{H}_{0}: \rho=0
\end{aligned}
$$

Under the null hypothesis, there is a unit root; under the alternative hypothesis, no unit root exists.

\section{Results and discussion}

\subsection{Analysis of energy-related $\mathrm{CO}_{2}$ emissions}

The levels of energy-related $\mathrm{CO}_{2}$ emissions in Chinese provincial capitals were calculated for the selected years using Eq. (1), as shown in Fig. 4. Fig. 4 demonstrates that $\mathrm{CO}_{2}$ emissions have increased in all cities in the study area during the studied period, and the increases witnessed in the second period (2000-2010) were much larger than those which characterise the first period (1990-2000). In addition, whilst the annual growth rate for 1990-2000 was $8.56 \%$, from 2000 onwards this growth rate accelerated significantly, reaching $9.90 \%$ in 2010 . In terms of the $\mathrm{CO}_{2}$ emissions produced by each city, Haikou was found to be the smallest emitter, with its emissions rising from 75.02 thousand tons in 1990 to 584.42 thousand tons in 2010. In contrast, Shanghai proved the largest emitter, with its emissions increasing from 3.34 million tons in 1990 to 18.87 million tons in 2010. Fig. 4 also 
Table 3

Description of landscape metrics.

\begin{tabular}{|c|c|c|c|}
\hline Indicators & Abbreviation & Equation & Description \\
\hline Total area & TA & $\mathrm{TA}=\sum_{j=1}^{n} a_{i j}(1 / 10000)$ & $a_{i j}=\operatorname{area}\left(\mathrm{m}^{2}\right)$ of patch $i j$ \\
\hline Largest patch index & LPI & $\mathrm{LPI}=\frac{\max _{j=1}^{\mathrm{n}}\left(a_{i j}\right)}{T A}(100)$ & $\begin{array}{l}a_{i j}=\text { area }\left(\mathrm{m}^{2}\right) \text { of patch } i j \\
\mathrm{TA}=\text { total landscape area }\left(\mathrm{m}^{2}\right)\end{array}$ \\
\hline $\begin{array}{l}\text { Area weighted mean shape } \\
\quad \text { index }\end{array}$ & AWMSI & AWMSI $=\sum_{i=1}^{m} \sum_{j=1}^{n}\left[\left(\frac{p_{i j}}{\min p_{i j}}\right)\left(\frac{a_{i j}}{T A}\right)\right]$ & $\begin{array}{l}m=\text { number of patch types } \\
n=\text { number of patches of a class } \\
P_{i j}=\text { perimeter of patch } i j \text { measured in number of cell }\end{array}$ \\
\hline $\begin{array}{l}\text { Area weighted mean patch } \\
\quad \text { fractal dimension }\end{array}$ & AWMPFD & $\mathrm{AWMPFD}=\sum_{i=1}^{m} \sum_{j=1}^{n}\left[\left(\frac{2 \ln \left(0.25 p_{i j}\right)}{\ln \left(a_{i j}\right)}\right)\left(\frac{a_{i j}}{T A}\right)\right]$ & $\begin{array}{l}p_{i j}=\text { perimeter of patch } i j \\
a_{i j}=\text { area of patch } i j \\
\mathrm{TA}=\text { total landscape area }\left(\mathrm{m}^{2}\right)\end{array}$ \\
\hline Mean perimeter area ratio & PARA_MN & PARA_MN $=\frac{\sum_{i=1}^{m} \sum_{j=1}^{n}\left(p_{i j} / a_{i j}\right)}{m n}$ & $\begin{array}{l}p_{i j}=\text { perimeter }(\mathrm{m}) \text { of patch } i j \\
a_{i j}=\text { area }\left(\mathrm{m}^{2}\right) \text { of patch } i j\end{array}$ \\
\hline Percentage of like adjacencies & PLADJ & PLADJ $=\left(\frac{\sum_{i=1}^{m} g_{i i}}{\sum_{i=1}^{m} \sum_{k=1}^{m} g_{i k}}\right)(100)$ & $\begin{array}{l}g_{i i}=\text { number of like adjacencies between pixels of class } i \text { based } \\
\text { on the double-count method } \\
g_{i k}=\text { number of adjacencies between class } i \text { and } k \text { based on the } \\
\text { double-count method }\end{array}$ \\
\hline Patch cohesion index & COHESION & COHESION $=\left[1-\frac{\sum_{i=1}^{m} \sum_{j=1}^{m} P_{i j}^{*}}{\sum_{i=-1}^{m} \sum_{j=1}^{n} P_{i j}^{*} \sqrt{a_{i j}^{*}}}\right] \cdot\left[1-\frac{1}{\sqrt{Z}}\right]^{-1}(100)$ & $\begin{array}{l}P_{i j}^{*}=\text { perimeter of patch } i j \text { in terms of number of cell surfaces, } \\
a_{i j}^{*}=\text { area of patch } i j \text { in terms of number of cells, } \\
Z=\text { total number of cells in the landscape }\end{array}$ \\
\hline Aggregation index & $\mathrm{AI}$ & $\mathrm{AI}=\left[\frac{g_{i i}}{\max \left(g_{i i}\right)}\right](100)$ & $\begin{array}{l}g_{i i}=\text { number of like adjacencies between class } i \text { based on the } \\
\text { single-count method }\end{array}$ \\
\hline Landscape shape index & LSI & $\mathrm{LSI}=\frac{0.25 \sum_{k=1}^{m} e_{i k}^{*}}{\sqrt{\mathrm{TA}}}$ & $\begin{array}{l}e_{i k}^{*}=\text { total length of edge in landscape between classes } i \text { and } k \\
\text { TA }=\text { total landscape area }\left(\mathrm{m}^{2}\right)\end{array}$ \\
\hline Contiguity & CONTIG & CONTIG $=\frac{\left[\frac{\sum_{r=1}^{x} c_{i j r}}{\alpha_{i j}}\right]-1}{v-1}$ & $\begin{array}{l}c_{i j r}=\text { contiguity value for pixel } \mathrm{r} \text { in patch } i j \\
v=\text { sum of the values in a } 3 \times 3 \text { moving window } \\
a_{i j}=\text { area of patch } i j \text { in terms of number of cells }\end{array}$ \\
\hline
\end{tabular}

displays the distribution overlay of $\mathrm{CO}_{2}$ emissions data in the form of a box chart, with the bottom and top of the box representing the 25th and 75th centiles for the selected years (1990, 2000 and 2010); the corresponding statistical descriptions are shown respectively in Table 4.

Once we had estimated the emissions for each city for the selected years, it was necessary to perform further analyses (of emission trends, spatial agglomeration of emissions, etc.).

Fig. 5 reviews the kernel density evolution path of $\mathrm{CO}_{2}$ emissions for the selected years. From Fig. 5, we find that, if the distribution of $\mathrm{CO}_{2}$ emissions can be considered to be highly concentrated at 1 million tons, it was mainly dispersed from 0.1 $\mathrm{t}$ to 3 million tons in 1990 . This indicates that the differences in $\mathrm{CO}_{2}$ emissions evidenced at city level were not particularly large in 1990. The kernel densities of 2000 and 2010 show that both the mean and the variance of $\mathrm{CO}_{2}$ emissions have been on the increase since 1990. In 2010, emissions were distributed from 1 to 4 million tons, with the most concentrated emission reading at 2 million tons.

Fig. 6 plots the distributions of a Moran scatter of $\mathrm{CO}_{2}$ emissions in Chinese provincial capital cities according to the temporal characteristics of global Moran's I, ${ }^{1}$ showing the local spatial correlation or spatial agglomeration of $\mathrm{CO}_{2}$ emissions geographically. An increasing trend of the autocorrelation can be clearly observed in Fig. 6, whereby Moran's I rises from 0.1784 in 1990 to 0.2779 in 2010 (where all are significant at 95\% confidence level via the randomisation assumption). This finding clearly reveals a trend of spatial concentration taking place in Chinese provincial capital cities. From the viewpoint of scatter distribution, $\mathrm{HH}$ and LL clusters constitute the main types of agglomeration seen over the studied period.

\subsection{Analysis of urban form aspects}

The estimated urban built-up areas of each city are displayed in Table 5 for the selected years. As indicated in Table 5, the built-up areas of each city rapidly expanded between 1990 and 2010. In

\footnotetext{
${ }^{1}$ Moran's I is a local indicator of spatial autocorrelation for the analysis of spatial clustering.
}

1990, the smallest total built-up area (Haikou) and the largest total built-up area (Shanghai) were $14.01 \mathrm{~km}^{2}$ and $502.43 \mathrm{~km}^{2}$ respectively, whereas in 2010 the smallest and largest areas increased to $50.67 \mathrm{~km}^{2}$ (Xining) and $1037.97 \mathrm{~km}^{2}$ (Beijing) respectively. In terms of the volume of expansion experienced by the cities that form the study area, Xining was found to experience the least expansion, with its area increasing from $37.16 \mathrm{~km}^{2}$ in 1990 to $50.67 \mathrm{~km}^{2}$ in 2010 (an increase of $13.51 \mathrm{~km}^{2}$ ); Beijing, in contrast, demonstrated the greatest expansion, with its area increasing from $415.87 \mathrm{~km}^{2}$ in 1990 to $1037.97 \mathrm{~km}^{2}$ in 2010 (an increase of $622.10 \mathrm{~km}^{2}$ ). From Table 5, we also find that the built-up areas of cities with large economies and high incomes were much higher than their counterparts (i.e., the less-developed areas). Fig. 7 displays the spatial patterns of urban built-up expansion from 1990 to 2010. Fig. 7 clearly identifies the dynamic sprawl path of the built-up areas in the 1990s, the 2000s and the 2010s.

With the support of pre-identifying urban sprawl indexes and spatial metrics applied to remotely sensed land cover data, a range of indicators (such as, TA, LPI, AWMSI, AWMPFD, PARA_MN, PALDJ, COHESION, AI, LSI and CONTIG) were calculated individually for each city using a computer software program (FRAGSTATS) designed to compute a wide variety of landscape metrics for categorical map patterns. The results of the calculation of these aspects of urban form indicate significant differences between cities in the changing trends and magnitudes of the indicators. In order to achieve clear descriptive statistics, a boxplot (a convenient way of graphically depicting groups of numerical data through their quartiles) was generated. Fig. 8 displays the variation of statistical urban form data without making any assumptions about the underlying statistical distribution. The spacing between the different parts of the box indicates the degree of dispersion (spread) and skewedness in the data, and shows outliers. Form the points distributed in the figure, we can visualise various L-estimators, notably the interquartile range, mean, median, minimum and maximum.

\subsection{Estimation results of the panel model}

Prior to conducting parameter estimations of panel data, the multicollinearity between regression models should be tested. 


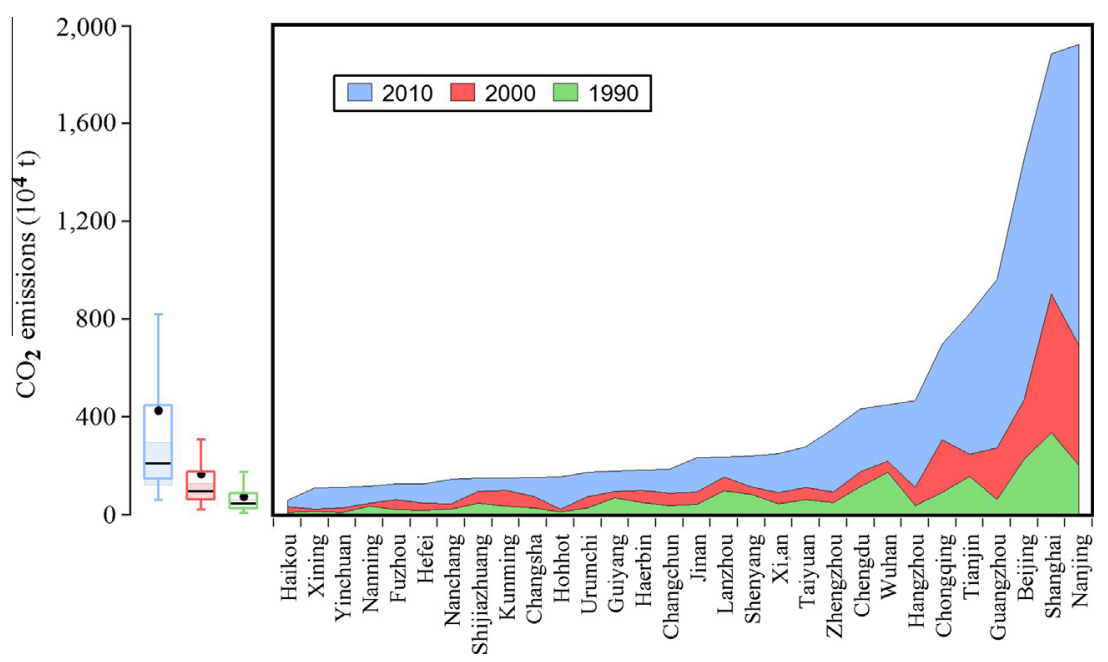

Fig. 4. $\mathrm{CO}_{2}$ emissions of provincial capitals with box chart distribution overlay for selected years.

Table 4

Summary statistics of $\mathrm{CO}_{2}$ emissions for selected years.

\begin{tabular}{|c|c|c|c|c|c|c|c|c|}
\hline Variable & Units & Mean & Median & Min & Max & Std. Dev & Skewness & Kurtosis \\
\hline $\mathrm{CO}_{2}$ emissions (1990) & $10^{4} \mathrm{t}$ & 72.877 & 44.856 & 7.502 & 334.39 & 75.536 & 1.895 & 6.297 \\
\hline $\mathrm{CO}_{2}$ emissions (2000) & $10^{4} \mathrm{t}$ & 165.762 & 95.249 & 21.611 & 902.512 & 199.266 & 2.461 & 8.655 \\
\hline $\mathrm{CO}_{2}$ emissions (2010) & $10^{4} \mathrm{t}$ & 426.007 & 208.990 & 58.442 & 1925.362 & 503.910 & 2.032 & 6.058 \\
\hline
\end{tabular}

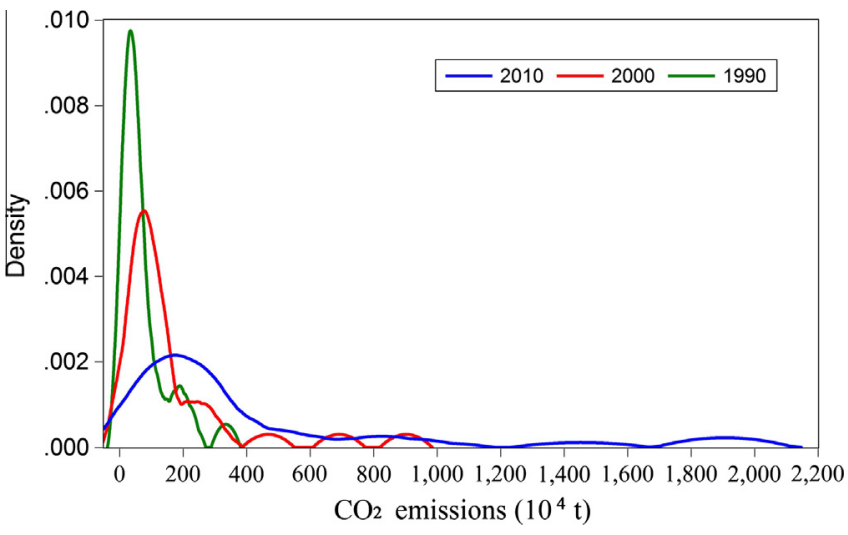

Fig. 5. Kernel density evolution of $\mathrm{CO}_{2}$ emissions for selected years.
Table 6 reports the results of correlations among the variables in this study. As indicated in Table 5, no high correlations existed in these variables. In addition, the results of the multicollinearity tests show that multicollinearity among all regression models was low, with variance inflation factors (VIF) no greater than 10 and condition indexes $(\mathrm{CI})$ less than 30 , indicating the independent variables did not suffer from the problem of severe multicollinearity. On the basis of these results, we were able to proceed in conducting the panel data analysis.

First, the stationarity of the dependent variable $\mathrm{CO}_{2}$ emissions needed to be tested. A type of panel unit root test, the LLC test, was utilised. The results from this test showed the variable to be stationary at the first difference, rejecting the null hypothesis at $5 \%$ level of significance. As such, the research could be undertaken without any specifications in difference. Given the condition that $T>k+1$ and $T=3$, the maximum value of $k$ was 1 , which implies that the regression model had at most one explanatory variable. The explanatory variables were separated into ten regression
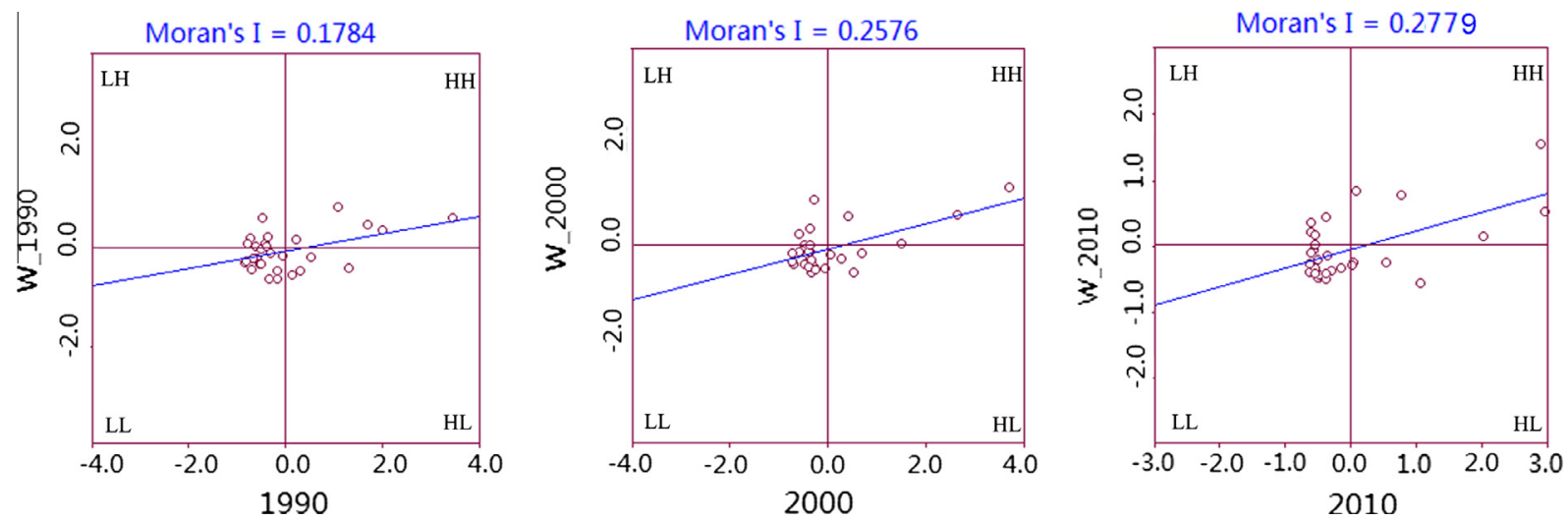

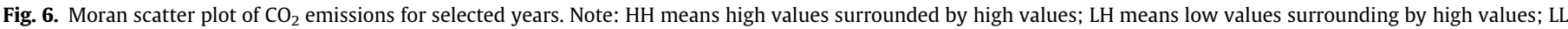
means low values surrounded by low values; HL means high values surrounded by low values. 
Table 5

Urban built-up areas of 30 Chinese provincial capital cities.

\begin{tabular}{|c|c|c|c|c|c|c|c|}
\hline \multirow[t]{2}{*}{ City } & \multicolumn{3}{|c|}{ Built-up area $\left(\mathrm{km}^{2}\right)$} & \multirow[t]{2}{*}{ City } & \multicolumn{3}{|c|}{ Built-up area $\left(\mathrm{km}^{2}\right)$} \\
\hline & 1990 & 2000 & 2010 & & 1990 & 2000 & 2010 \\
\hline Beijing & 415.87 & 877.80 & 1037.97 & Lanzhou & 90.85 & 92.15 & 117.86 \\
\hline Changchun & 163.93 & 180.75 & 279.32 & Nanchang & 53.16 & 63.37 & 136.75 \\
\hline Changsha & 83.21 & 92.75 & 168.26 & Nanjing & 169.62 & 246.87 & 583.74 \\
\hline Chengdu & 138.36 & 226.22 & 608.53 & Nanning & 70.40 & 128.71 & 151.83 \\
\hline Chongqing & 129.04 & 165.08 & 195.54 & Shanghai & 502.43 & 680.33 & 837.39 \\
\hline Fuzhou & 75.71 & 93.46 & 130.74 & Shenyang & 218.89 & 228.80 & 329.74 \\
\hline Guangzhou & 174.47 & 313.44 & 414.53 & Shijiazhuang & 84.77 & 130.58 & 151.73 \\
\hline Guiyang & 64.96 & 68.67 & 78.61 & Taiyuan & 176.58 & 221.52 & 247.44 \\
\hline Harbin & 137.40 & 146.10 & 190.70 & Tianjin & 339.14 & 380.80 & 542.36 \\
\hline Haikou & 14.01 & 54.03 & 67.75 & Wuhan & 220.10 & 243.81 & 440.63 \\
\hline Hangzhou & 91.76 & 133.11 & 256.07 & Urumqi & 185.17 & 221.70 & 245.48 \\
\hline Hefei & 93.36 & 110.49 & 247.63 & Xi'an & 149.23 & 182.74 & 210.67 \\
\hline Hohhot & 85.92 & 124.19 & 121.23 & Xining & 37.16 & 38.93 & 50.67 \\
\hline Jinan & 111.81 & 163.32 & 223.02 & Yinchuan & 32.67 & 47.35 & 84.54 \\
\hline Kunming & 91.48 & 143.82 & 243.11 & Zhengzhou & 113.10 & 163.91 & 235.29 \\
\hline
\end{tabular}

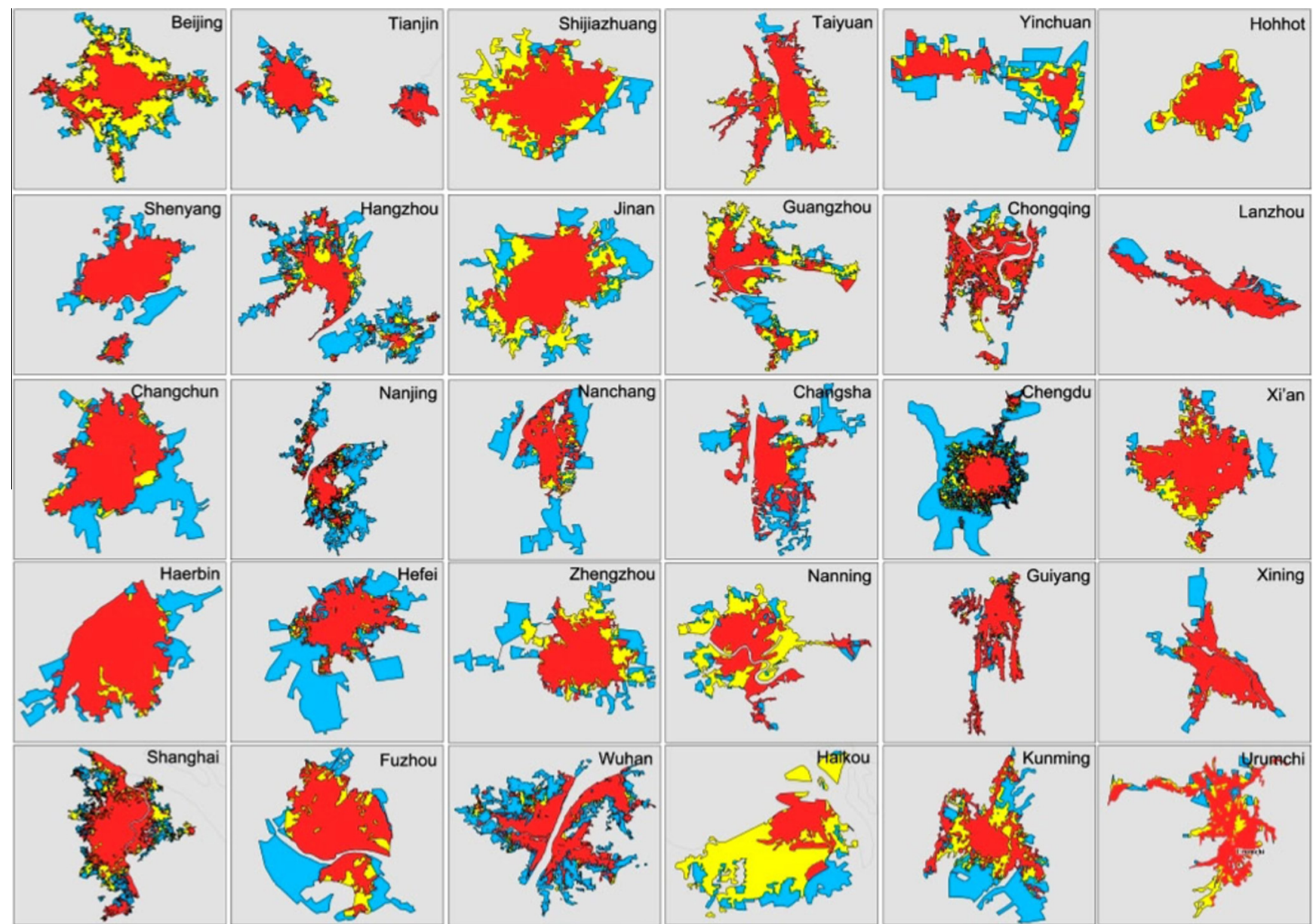

1990 Urban Built-up Area

Urban Built-up Area in 1990-2000

Urban Built-up Area in 2000-2010

Fig. 7. Spatial patterns of urban built-up areas of 30 Chinese provincial capital cities.

models in order to properly estimate the relationship between $\mathrm{CO}_{2}$ emissions and urban form. Since models I-X are static panel models, they could be estimated using either the fixed effects estimator or the random effects estimator. Hausman tests were further conducted, with results rejecting the null hypothesis of random effects, indicating that the fixed effects estimator was suitable for the ten models developed. Table 7 displays the coefficients estimated from the panel data analysis. These results identify several associations between urban form and $\mathrm{CO}_{2}$ emissions, thereby suggesting that the nature of the links between urban form and $\mathrm{CO}_{2}$ emissions are in fact discernible at the provincial capital city level in China. Organised in terms of urban form aspects, we describe 

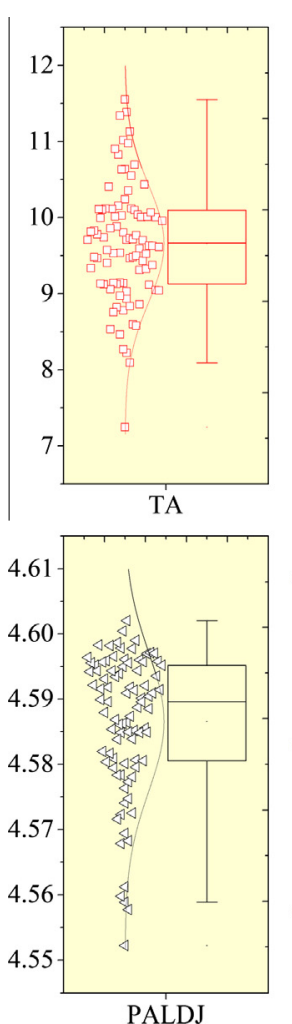

PALDJ
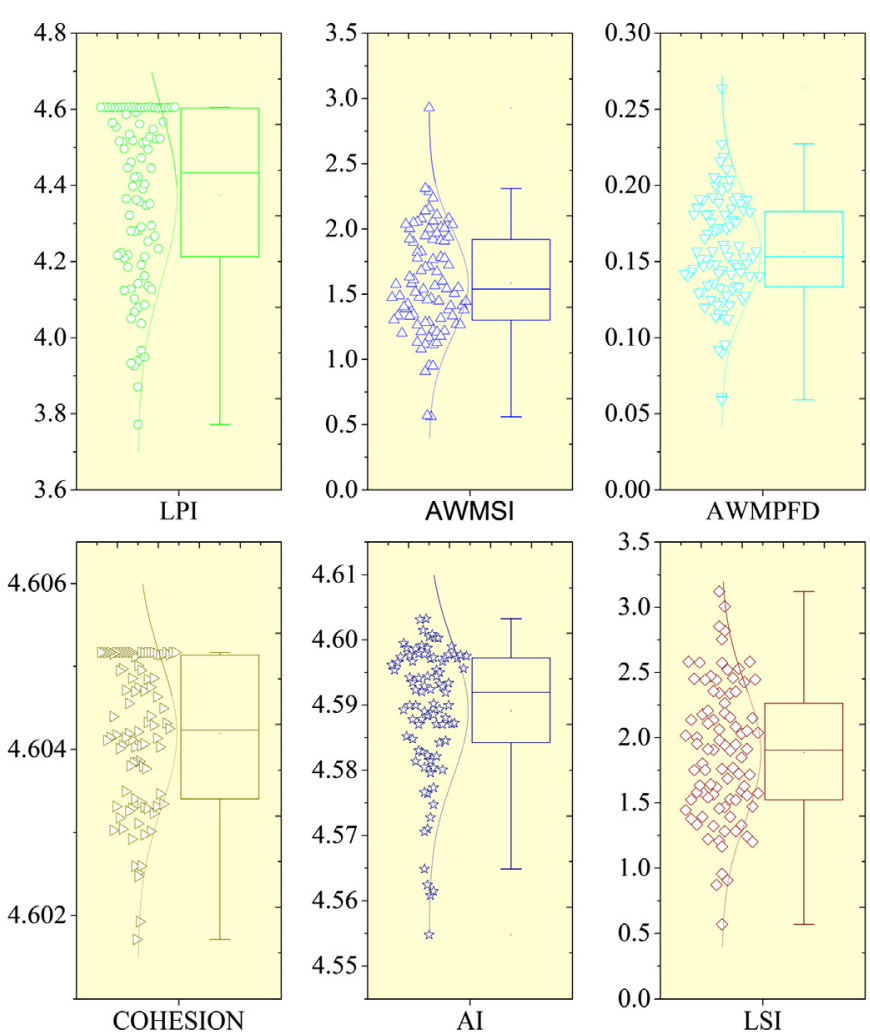
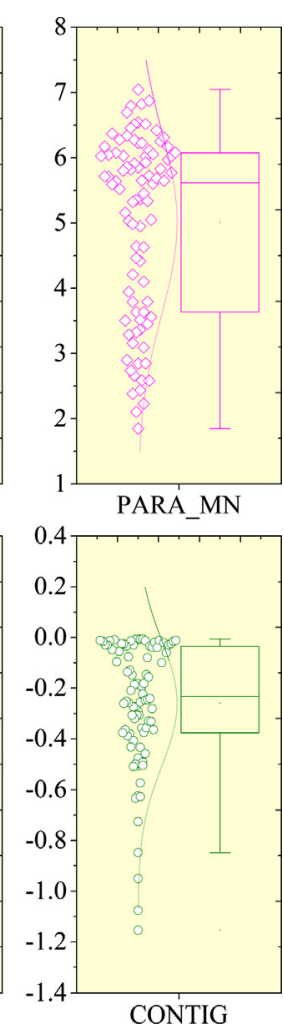

Fig. 8. Box chart of urban form aspects with scatter plot and distribution overlay.

Table 6

Correlation test results.

\begin{tabular}{|c|c|c|c|c|c|c|c|c|c|c|}
\hline & TA & LPI & AWMSI & AWMPFD & PARA_MN & PALDJ & COHESION & AI & LSI & CONTIG \\
\hline $\mathrm{TA}$ & 1.000 & & & & & & & & & \\
\hline LPI & $-0.003^{* * *}$ & 1.000 & & & & & & & & \\
\hline AWMSI & $0.284^{* * *}$ & $-0.081^{* * * *}$ & 1.000 & & & & & & & \\
\hline AWMPFD & $0.125^{* * *}$ & $-0.147^{* * *}$ & $0.483^{* *}$ & 1.000 & & & & & & \\
\hline PARA_MN & $0.326^{* *}$ & $-0.169^{* * *}$ & $0.445^{* *}$ & $0.410^{* *}$ & 1.000 & & & & & \\
\hline PALDJ & $0.426^{* * *}$ & $0.338^{* * *}$ & $-0.604^{* * *}$ & $-0.712^{* * *}$ & $-0.225^{* * *}$ & 1.000 & & & & \\
\hline COHESION & $0.340^{\text {*** }}$ & $0.561^{* *}$ & $-0.101^{* * * *}$ & $-0.214^{* * *}$ & $-0.160^{* * *}$ & $0.662^{* *}$ & 1.000 & & & \\
\hline AI & $0.344^{* * *}$ & $0.350^{* * * *}$ & $-0.654^{* * *}$ & $-0.701^{* * *}$ & $-0.260^{* * *}$ & $0.695^{* *}$ & $0.653^{* * * *}$ & 1.000 & & \\
\hline LSI & $0.242^{* * *}$ & $-0.480^{* * * *}$ & $0.583^{* * * *}$ & $0.597^{* * *}$ & $0.486^{* *}$ & $-0.717^{* *}$ & $-0.504^{* * *}$ & $-0.468^{* * *}$ & 1.000 & \\
\hline CONTIG & $-0.355^{* * *}$ & $-0.081^{* * * *}$ & $-0.304^{* * *}$ & $-0.244^{* * *}$ & $-0.703^{* *}$ & $-0.019^{* * *}$ & $-0.143^{* * *}$ & $0.012^{* * * *}$ & $-0.211^{* * *}$ & 1.000 \\
\hline
\end{tabular}

Note: All values are taken the natural logarithm.

${ }^{* *}$ Denotes significance at $5 \%$ level.

${ }^{* * *}$ Denotes significance at $1 \%$ level.

here only those relationships between urban form and $\mathrm{CO}_{2}$ emissions that were statistically significance at less than 5\% level (TA, COHESION, AI, CONTIG, AWMSI, AWMPFD and LSI).

Model I was used to test the effects of urban expansion on $\mathrm{CO}_{2}$ emissions. The coefficient of TA in logarithmic form was expected to be positive and the estimation result obtained in relation Model I was consistent with that expectation. With the implementation of its "Reform and Opening-up" policy in the late 1970s, China has witnessed (and is still witnessing) fast-paced urban development. Over the past two decades, urbanisation levels in China's 30 provincial capitals have increased spectacularly. This has resulted in several effects. Firstly, the expansion of urban areas for living and infrastructure has reduced vegetation and lead to a decrease in the size of carbon sinks - an effect which can be expected to pose negative consequences for carbon storage and result in many environmental changes such as the urban heat island effect and global warming. Secondly, rapid urbanisation in these 30 provincial capitals has brought millions of people from rural areas to cities and towns every year. This migration has led to increases in the demand for urban energy supplies and the production of a large volume of $\mathrm{CO}_{2}$ emissions. In addition, the growth of population directly has also resulted in tremendous increases in consumption (daily living, working), which accelerate the process of industrial production and resource consumption, leading to further growth in $\mathrm{CO}_{2}$ emissions. Thus, unsurprisingly, the findings of this study support the conclusion that the rapid growth of urban areas has brought about a corresponding increase in $\mathrm{CO}_{2}$ emissions.

The other six landscape metrics used in this study described two components of urban form [12]: urban continuity and urban shape complexity. The landscape metrics belonging to urban continuity included COHESION, AI and CONTIG; those used to describe urban shape complexity included AWMSI, AWMPFD and LSI.

Urban continuity denotes the degree to which the urban landscape is aggregated and connected. Higher urban continuity means that urban areas are less scattered, with more continuous and less interspersed development. The higher the value of urban continuity, 
Table 7

Coefficients estimated from panel data analysis.

\begin{tabular}{|c|c|c|c|c|c|c|c|c|}
\hline Model & Independent variables & Coefficient & Constant & $R$-square & F-statistic & Prob (F-statistic) & AIC & $N$ \\
\hline Model I & $\ln T A$ & $\begin{array}{l}1.9680^{* * * *} \\
(0.1544)\end{array}$ & $\begin{array}{l}-14.304^{* * * *} \\
(1.4923)\end{array}$ & 0.8885 & 15.6765 & 0.0000 & 1.6248 & 90 \\
\hline Model II & $\ln L P I$ & $\begin{array}{l}0.5297 \\
(1.0212)\end{array}$ & $\begin{array}{l}2.3826 \\
(4.4688)\end{array}$ & 0.5837 & 2.7570 & 0.0004 & 2.9426 & 90 \\
\hline Model VI & $\ln P A L D J$ & $\begin{array}{l}-0.6372 \\
(0.4504)\end{array}$ & $\begin{array}{l}5.7113^{* * *} \\
(0.7209)\end{array}$ & 0.6955 & 2.8951 & 0.0002 & 2.9138 & 90 \\
\hline Model VII & InCOHESION & $\begin{array}{l}-1.4883^{* *} \\
(0.7190)\end{array}$ & $\begin{array}{l}6.3454^{* * * *} \\
(0.7460)\end{array}$ & 0.7141 & 3.1292 & 0.0000 & 1.8667 & 90 \\
\hline Model VIII & $\ln A I$ & $\begin{array}{l}-0.7999 \\
(1.2641)\end{array}$ & $\begin{array}{l}3.6324^{* * *} \\
(0.5801)\end{array}$ & 0.8508 & 5.9271 & 0.0000 & 2.9241 & 90 \\
\hline Model X & $\operatorname{lnCONTIG}$ & $\begin{array}{l}-2.0580^{* *} \\
(0.8338)\end{array}$ & $\begin{array}{l}4.1680^{* * *} \\
(0.2348)\end{array}$ & 0.8209 & 3.2210 & 0.0000 & 2.8489 & 90 \\
\hline Model III & $\ln A W M S I$ & $\begin{array}{l}0.7876 \\
(1.1161)\end{array}$ & $\begin{array}{l}-3.5645^{* * *} \\
(0.5325)\end{array}$ & 0.7650 & 2.4024 & 0.0000 & 2.3706 & 90 \\
\hline Model IV & $\ln A W M P F D$ & $\begin{array}{l}0.9617^{\text {***** }} \\
(1.7383)\end{array}$ & $\begin{array}{l}-4.4223^{* * *} \\
(0.8004)\end{array}$ & 0.8246 & 5.1750 & 0.0000 & 2.5292 & 90 \\
\hline Model V & InPARA_MN & $\begin{array}{l}0.1971 \\
(0.1515)\end{array}$ & $\begin{array}{l}3.7132^{* * *} \\
(0.7646)\end{array}$ & 0.5934 & 2.8705 & 0.0002 & 2.9188 & 90 \\
\hline Model IX & $\ln L S I$ & $\begin{array}{l}0.9889^{* *} \\
(0.3902)\end{array}$ & $\begin{array}{l}-4.5631^{* * *} \\
(0.7411)\end{array}$ & 0.8288 & 3.2471 & 0.0000 & 2.8438 & 90 \\
\hline
\end{tabular}

Note: Robust standard errors in parentheses for models I to X.

${ }^{* *}$ Denotes significance at $5 \%$ level.

*** Denotes significance at $1 \%$ level.

the less fragmented an urban area is. Urban development with high aggregation and connectedness should lead to shorter commuting distance between residences and places of work. As described previously, the variable COHESION estimates the connectedness of urban areas; AI and CONTIG are measures of the aggregation of urban areas. The lower the values of COHESION, AI and CONTIG, the more compact the development pattern of an urban area is. From Table 7, we find that the variables COHESION, AI and CONTIG all demonstrated significant negative correlations with respect to $\mathrm{CO}_{2}$ emissions. These results are in line with the results of a number of other recent studies. For instance, Bereitschaft and Debbage [12] employed a similar measure in their study and found that more contiguous urban areas experienced, on average, significantly lower levels of $\mathrm{CO}_{2}$. Similarly, Ou et al. [10] also found urban expansion within an aggregated and continuous pattern to positive correlate with the reduction of $\mathrm{CO}_{2}$ emissions. In addition, using Beijing as an example, Wang et al. [22] found that a more decentralised urban form is conducive to the increase of transport-related $\mathrm{CO}_{2}$ emissions. The results of similar studies have also demonstrated that more compact urban areas can lead to less use of private automobiles, shorter travel distances, a higher efficiency of city operation, higher urban land-use intensity and less consumption of energy resources. The findings of this study indicate that a compact and continuous urban area is highly beneficial for fast-growing cities, in order for them to reduce $\mathrm{CO}_{2}$ emissions and realise urban sustained development. The results are also useful for urban planners, assisting them in identifying effective strategies for low-carbon urban planning and spatial optimisation.

Urban shape complexity was utilised in this study in order to estimate the potential links between special attributes (for instance, shape of boundary or landscape) of urban form and $\mathrm{CO}_{2}$ emissions. Urban shape complexity provides a measure of the regularity or the "jaggedness" of the shape of an urban boundary. In general, the higher the value of shape complexity is, the more irregular the urban landscape is. Less compact urban landscapes with highly complex, irregular boundaries can be expected to increase the time and distance of common commuting. As indicated in Table 7, the variables AWMSI, AWMPFD and LSI were found to exert significant positive impacts on $\mathrm{CO}_{2}$ emissions. AWMSI is used to reflect the landscape structure by calculating the complexity of urban patches according to their size. AWMPFDI measures the irregularity of urban patches' shapes, which implies the unplanned growth of an urban area. The shape of the urban area will become more irregular if the fractal dimension index increases. LSI can be interpreted as a measure of the overall geometric complexity of the landscape. The results of estimating AWMSI, AWMPFD and LSI indicate that $\mathrm{CO}_{2}$ emissions increased as the urban landscape within these 30 provincial capital cities exhibited more complex and irregular spatial patterns. The main reason for this phenomenon may be that irregular urban landscapes significantly increase the number and duration of automobile trips by increasing the movements of people from living areas to the working areas. Given the above, the study identified a significant association between urban shape complexity (which indicates more complex urban spatial patterns) and $\mathrm{CO}_{2}$ emissions.

\section{Conclusions and policy implications}

Global warming is an indisputable fact, and it has become an inevitable threat to our lives and environment. Further, it is urban areas that are primarily responsible for the rising temperatures resulting from the effects of today's high levels of $\mathrm{CO}_{2}$ emissions [59-62]. Currently, it is unanimously recognised that urban form can strongly impact on a fast-growing city's contribution to global climate change through the production of $\mathrm{CO}_{2}$ emissions [10], and as such, it is clearly necessary to undertake appropriate strategic spatial planning and urban design measures in order to reduce $\mathrm{CO}_{2}$ emissions and thereby address the anticipated impact of global warming. Despite this urgent imperative, existing literature engaging in the task of quantifying the impacts of urban forms on $\mathrm{CO}_{2}$ emissions is limited. In order to deal with this deficiency, this study has aimed to explore the nature of links between urban form and $\mathrm{CO}_{2}$ emissions using panel data for 30 provincial capital cities in China, remotely sensed data, and socioeconomic data from 1990 to 2010.

In this study, we calculated $\mathrm{CO}_{2}$ emissions for the urban areas of 30 provincial capital cities in China taking the period 1990-2010 into consideration, and then proceeded to identify the built-up area of each city using remotely sensed images. In addition, quantitative indicators relating to urban form were selected and quan- 
tified using spatial (landscape) metrics for the urban built-up areas of each provincial capital city. Panel data analysis was subsequently utilised in order to estimate the associations between urban form and $\mathrm{CO}_{2}$ emissions.

From the analysis of $\mathrm{CO}_{2}$ emissions, we found the emissions for all the cities to have increased during the study period, and that regional inequality in $\mathrm{CO}_{2}$ emissions among provincial capital cities also increased (albeit gradually) from 1990 to 2010. In addition, on the basis of results obtained using global Moran's I, the study revealed an increasing trend towards autocorrelation (spatial dependence) taking place in Chinese provincial capitals. The urban areas of each city were also shown to have undergone rapid expansion from 1990 to 2010, with significant differences being presented in terms of both the character and magnitude of changes evident in the urban form of each city.

Parameter estimations made using the panel data model indicated that the individual variable coefficients exhibited important but different impacts with respect to their effect upon $\mathrm{CO}_{2}$ emissions. In order to obtain a clearer analysis, ten indicators relating to urban forms were initially classified in accordance with three key aspects [12]: urban expansion (TA), urban continuity (COHESION, AI and CONTIG) and urban shape complexity (AWMSI, AWMPFD and LSI). Urban sprawl was found to inevitably accelerate the increase of $\mathrm{CO}_{2}$ emissions. This is because, on the one hand, the growth of urban areas leads to a reduction of carbon sinks and an increase in resources consumption, and, on the other, it incites millions of people to move from rural areas moved to cities and towns across China every year through rapid urbanisation processes. This migration and the lifestyle changes it necessitates lead to an increase in $\mathrm{CO}_{2}$ emissions. Urban continuity (high COHESION, $\mathrm{AI}$ and CONTIG) was found to be negatively correlated with $\mathrm{CO}_{2}$ emissions, indicating that an aggregated and continuous urban development pattern can in fact help reduce $\mathrm{CO}_{2}$ emissions. Conversely, urban shape complexity (high AWMSI, AWMPFD and LSI) was found to exert a positive influence on $\mathrm{CO}_{2}$ emissions, meaning that fragmented or irregular urban areas (and patterns of land use) contribute to the increase of $\mathrm{CO}_{2}$ emissions.

The findings of this study represent a contribution to the existing literature and suggest a series of meaningful theoretical and policy implications. The study found that, given the significant contribution urban areas make to global climate change, the impact that different urban form patterns exert in relation to $\mathrm{CO}_{2}$ emissions intensifies in contexts of rapid urbanisation. The results of this study clearly point out that individual urban form indicators exert important but different influences in relation to $\mathrm{CO}_{2}$ emissions. In order to formulate effective emission-reducing policies, in the future urban planning practice should consider the impacts of different urban form patterns on $\mathrm{CO}_{2}$ emissions. It is, however, also recognised that cities are required to make substantial contributions to economic development, and that steady and fast economic growth must always be the primary goal of Chinese decision makers. As such, a prerequisite to realising emission reduction targets must be the maintenance of economic development, characterised by gross domestic product (GDP). Given these conditions, the Chinese government faces the significant challenge of both reducing urban $\mathrm{CO}_{2}$ emissions while also maintaining economic growth in cities where rapid development is still necessary and important. On the basis of previous research, we now know that reducing energy use and improving energy efficiency are the most effective measures to reduce $\mathrm{CO}_{2}$ emissions. However, whilst energy use is the direct driving force behind economic development in China's current stage of development - and it is thus not the most feasible alternative to reduce $\mathrm{CO}_{2}$ emissions at the cost of sacrificing economic growth in the future $[6,9,10]$ - it must also be recognised that energy technology equipment and policy management are both still relatively backward present. Moreover, a bottleneck still exists in terms of technology and money for energy conservation and emission mitigation [63]. As such, in addition to reducing energy use and improving energy efficiency, the results of this study support the design of rational urban form through spatial planning and urban management, and indicate that such measures may in fact constitute an effective alternative in addressing the issue of emission reductions in relation to Chinese cities. In support of such a development, a better understanding of the quantitative relationships between urban forms and $\mathrm{CO}_{2}$ emissions is important and indeed necessary for Chinese policymakers at various levels (both central and local) when formulating future urban development plans. We identify the major results of the presented study, and propose a three-pronged strategy to get Chinese cities onto the low-carbon pathway. First, China must control the rapid expansion of major cities. Under the context of rapid urbanisation, Chinese cities should increase the green areas and, in turn, increase carbon sinks. Urban sprawl incites millions of people to move from rural areas to cities and towns across China every year. Thus, it should also make more effort to improve the public low-carbon awareness, strengthen the generalisation of a low-carbon economy. Second, Chinese cities should increase urban compactness to mitigate $\mathrm{CO}_{2}$ emissions. According to our conclusions, lower $\mathrm{CO}_{2}$ emissions level can be achieved through cities that are more compact. However, various environmental problems resulting from increased compactness may appear when public service investment is limited and the income distribution system is distorted. Thus, a key focus should be that policy should identify an optimum degree of urban compactness that, on the one hand, will prevent disadvantages associated with overcrowding, and, on the other, mitigate the $\mathrm{CO}_{2}$ emissions effectively. Third, Chinese cities should optimise the patterns of land use because of the fragmented or irregular urban areas contribute to the increase of $\mathrm{CO}_{2}$ emissions. Urban planners should consider the urban shape complexity when formulate future urban development strategies. Shape complexity (perimeter-to-area ratio) can be interpreted as the "jaggedness" of the urban boundary as well as the porosity (i.e., the intermixing of urban and nonurban land cover) of the urban landscape. Therefore, decrease shape complexity when controlling urban development can reduce urban $\mathrm{CO}_{2}$ emissions effectively. Ultimately, this knowledge will allow them to address emission reductions and to achieve more sustainable economic growth [64]. Based on the analysis set out in this paper, the empirical findings of this study hold important implications for action on the path towards developing low-carbon cities in China.

\section{Acknowledgements}

We would like to thank Mr. Mao Hanying, Professor and economic geographical specialist, for his valuable comments on the academic ideas within this manuscript. This work was supported by the National Natural Science Foundation of China (41371177) and the State Key Program of National Natural Science of China (71433008).

\section{References}

[1] Wang SJ, Fang CL, Guan XL, Pang B, Ma HT. Urbanization, energy consumption, and $\mathrm{CO}_{2}$ emissions in China: a panel data analysis of China's province. Appl Energy 2014;136:738-49.

[2] Van de Wal RSW, de Boer B, Lourens LJ, Kohler P, Bintanja R. Reconstruction of a continuous high-resolution $\mathrm{CO}_{2}$ record over the past 20 million years. Clim Past 2011;7(4):1459-69.

[3] Intergovernmental Panel on Climate Change (IPCC). Climate change. The fourth assessment report of the intergovernmental panel on climate change. England: Cambridge University Press; 2007.

[4] United Nations. United Nations, New York: World urbanization prospects, the 2009 revision; 2010.

[5] International Statistical Yearbook. Beijing: Chinese Statistics Press; 2012. 
[6] Wang ZH, Yin FC, Zhang YX, Zhang X. An empirical research on the influencing factors of regional $\mathrm{CO}_{2}$ emissions: evidence from Beijing city, China. Appl Energy 2012;100:277-84.

[7] Liu Z, Guan DB, Crawford-Brown D, Zhang Q, Liu JG. A low-carbon road map for China. Nature 2013;500(7461):143-5.

[8] Wang P, Wu WS, Zhu BZ, Wei YM. Examining the impact factors of energyrelated $\mathrm{CO}_{2}$ emissions using the STIRPAT model in Guangdong Province, China. Appl Energy 2013;106:65-71.

[9] Wang SJ, Fang CL, Wang Y, Huang YB, Ma HT. Quantifying the relationship between urban development intensity and carbon dioxide emissions using a panel data analysis. Ecol Indic 2014;49:121-31.

[10] Ou JP, Liu XP, Li X, Chen YM. Quantifying the relationship between urban forms and carbon emissions using panel data analysis. Landscape Ecol 2013;28:1889-907.

[11] Ewing R, Rong F. The impact of urban form on U.S. residential energy use. Hous Policy Debate 2008;19(1):1-30.

[12] Bereitschaft B, Debbage K. Urban form, air pollution, and $\mathrm{CO}_{2}$ emissions in large U.S. metropolitan areas. Prof Geog 2013;65(4):612-35.

[13] Xu SC, He ZX, Long RY. Factors that influence carbon emissions due to energy consumption in China: decomposition analysis using LMDI. Appl Energy 2014;127:182-93.

[14] Hawkes $\mathrm{AD}$. Long-run marginal $\mathrm{CO}_{2}$ emissions factors in national electricity systems. Appl Energy 2014;125:197-205.

[15] Wang SJ, Fang CL, Ma HT, Wang Y, Qin J. Spatial differences and multimechanism of carbon footprint based on GWR model in provincial China. J Geograph Sci 2014;24(4):612-30.

[16] Tsai YH. Quantifying urban form: compactness versus sprawl. Urban Stud 2005;42(1):141-61.

[17] Newman PWG, Kenworthy JR. The land use-transport connection - an overview. Land Use Policy 1996;13(1):1-22.

[18] Anderson WP, Kanaroglou PS, Miller EJ. Urban form, energy and the environment: a review of issues, evidence and policy. Urban Stud 1996;33 (1):7-35.

[19] Camagni R, Gibelli M, Rigamonti P. Urban mobility and urban form: the social and environmental costs of different patterns of urban expansion. Ecol Econ 2002;40(2):199-216.

[20] Dietzel C, Oguz H, Hemphill JJ, Clarke KC, Gazulis N. Diffusion and coalescence of the Houston metropolitan area: evidence supporting a new urban theory. Environ Plan B 2005;32(2):231-46.

[21] Liu Y, Song Y, Arp HP. Examination of the relationship between urban form and urban eco-efficiency in china. Habitat Int 2012;36(1):171-7.

[22] Wang YJ, Hayashi Y, Chen J, Li Q. Changing urban form and transport $\mathrm{CO}_{2}$ emissions: an empirical analysis of Beijing, China. Sustainability 2014;6 (7):4558-79.

[23] Ishii S, Tabushi S, Aramaki T, Hanaki K. Impact of future urban form on the potential to reduce greenhouse gas emissions from residential, commercial and public buildings in Utsunomiya, Japan. Energy Policy 2010;38 (9):4888-96.

[24] Hankey S, Marshall JD. Impacts of urban form on future US passenger-vehicle greenhouse gas emissions. Energy Policy 2010;38(9):4880-7.

[25] Stone B, Rodgers MO. Urban form and thermal efficiency: how the design of cities influences the urban heat island effect. J Am Plann Assoc 2001;67 (2):186-98.

[26] Glaeser EL, Kahn ME. The greenness of cities: carbon dioxide emissions and urban development; 2008. <http://en. Scientific commons.Org>.

[27] Liu XC, Sweeney J. Modelling the impact of urban form on household energy demand and related $\mathrm{CO}_{2}$ emissions in the Greater Dublin Region. Energy Policy 2012;46:359-69.

[28] Harmaajarvi IA, Huhdanmaki P, Lahti, P. Urban form and greenhouse gas emissions; 2002. <http://www.ymparisto.fi/download.asp? contentid=14207\& lan=en.>

[29] Banister D. Energy, quality of life and the environment: the role of transport. Transport Rev 1996;16(1):23-35.

[30] Christen AN, Coops C, Crawford BR, Kellett R, Liss KN, Olchovski I, et al. Validation of modelled carbon-dioxide emissions from an urban neighbourhood with direct eddy-covariance measurements. Atmos Environ 2011;45:6057-69.

[31] Makidoa Y, Dhakalb S, Yamagatac Y. Relationship between urban form and $\mathrm{CO}_{2}$ emissions: evidence from fifty Japanese cities. Urban Clim 2012;2(12):55-67.

[32] Ma J, Liu ZL, Chai YW. The impact of urban form on $\mathrm{CO}_{2}$ emission from work and non-work trips: the case of Beijing, China. Habitat Int 2015;47:1-10.

[33] Ye H, He XY, Song Y, Li XH, Zhang GQ, Lin T, et al. A sustainable urban form: the challenges of compactness from the viewpoint of energy consumption and carbon emission. Energy Build 2015;93:90-8.

[34] Lee S, Lee B. The influence of urban form on GHG emissions in the US household sector. Energy Policy 2014;68:534-49.

[35] Qin B, Shao R. The impacts of urban form on household carbon emissions: a case study on neighbourhoods. City Plan Rev 2012;36(6):1-6.
[36] Intergovernmental Panel on Climate Change (IPCC). IPCC guidelines for national greenhouse gas inventories. Intergovernmental panel on climate change. London: IPCC; 2006.

[37] Al-mulali U. Factors affecting $\mathrm{CO}_{2}$ emission in the Middle East: a panel data analysis. Energy 2012;4(1):564-9.

[38] Du LM, Wei C, Cai SH. Economic development and carbon dioxide emissions in China: provincial panel data analysis. China Econ Rev 2012;23(2):371-84.

[39] Zhou DC, Zhao SQ Liu SG, Zhang LX. Spatiotemporal trends of terrestrial vegetation activity along the urban development intensity gradient in China's 32 major cities. Sci Total Environ 2014;488:136-45.

[40] Peters GP, Marland G, Le QC, Boden T, Canadell JG, Raupach MR. Rapid growth in $\mathrm{CO}_{2}$ emissions after the 2008-2009 global financial crisis. Nat Clim Change 2012;2(1):2-4.

[41] Su YX, Chen XZ, Li Y, Liao JS, Ye YY, Zhang HG, et al. China's 19-year city-level carbon emissions of energy consumptions, driving forces and regionalized mitigation guidelines. Renew Sustain Energy Rev 2014;35:231-43.

[42] Huang B, Meng LN. Convergence of per capita carbon dioxide emissions in urban China: a spatio-temporal perspective. Appl Geogr 2013;40:21-9.

[43] Liu Y, Song Y, Song XD. An empirical study on the relationship between urban compactness and $\mathrm{CO}_{2}$ efficiency in China. Habitat Int 2014;41:92-8.

[44] Liu J, Zhan J, Deng X. Spatio-temporal patterns and driving forces of urban land expansion in China during the economic reform era. Ambio 2005;34(6):450-5.

[45] Liu J, Liu M, Deng X, Zhuang D, Zhang Z, Luo D. The land use and land cover change database and its relative studies in China. J Geograph Sci 2002; $12: 275-82$.

[46] Herold M, Scepan J, Clarke KC. The use of remote sensing and landscape metrics to describe structures and changes in urban land uses. Environ Plan A 2002;34:1443-58.

[47] Luck M, Wu JG. A gradient analysis of urban landscape pattern: a case study from the Phoenix metropolitan region, Arizona, USA. Landscape Ecol 2002;17:327-39.

[48] Herold M, Goldstein NC, Clarke KC. The spatiotemporal form of urban growth: measurement, analysis and modelling. Remote Sens Environ 2003;86:286-302.

[49] Li X, Yeh AGO. Analyzing spatial restructuring of land use patterns in a fast growing region using remote sensing and GIS. Landscape Urban Plan 2004:69:335-54.

[50] Huang JG, Lu XX, Sellers JM. A global comparative analysis of urban form: applying spatial metrics and remote sensing. Landscape Urban Plan 2007;82:184-97.

[51] Wu J, Jenerette GD, Buyantuyev A, Redman CL. Quantifying spatiotemporal patterns of urbanization: the case of the two fastest growing metropolitan regions in the United States. Ecol Complex 2011;8:1-8.

[52] Aithal BH, Sanna DD. Insights to urban dynamics through landscape spatial pattern analysis. Int J Appl Earth Obs 2012;18:329-43.

[53] Su S, Xiao R, Jiang Z, Zhang Y. Characterizing landscape pattern and ecosystem service value changes for urbanization impacts at an eco-regional scale. Appl Geogr 2012;34:295-305.

[54] McGarigal K, Marks BJ. Spatial pattern analysis program for quantifying landscape structure, vol. 606. Dolores (CO): PO Box; 1994. p. 67.

[55] Huang SL, Wang SH, Budd WW. Sprawl in Taipei's peri-urban zone: responses to spatial planning and implications for adapting global environmental change. Landscape Urban Plan 2009;90:20-32.

[56] McGarigal K, Cushman SA, Ene E. FRAGSTATS v4: Spatial pattern analysis program for categorical and continuous maps. Computer software program produced by the authors at the University of Massachusetts, Amherst; 2012. <http://www.umass.edu/landeco/research/fragstats/fragstats.html>.

[57] Hausman JA. Specification tests in econometrics. Econometrica 1978;46 (6):1251-71.

[58] Levin A, Lin CF, Chu CSJ. Unit root tests in panel data: asymptotic and finitesample properties. J Econometrics 2002;108(1):1-24.

[59] Liu SW, Zhang PY, Jiang XL, Lo K. Measuring sustainable urbanization in China: a case study of the coastal Liaoning area. Sustain Sci 2013;8:585-94.

[60] Fang CL, Xie YC. Planning and designing hi-tech parks: Chinese practices in the reform era. Environ Plan B 2008:35(1):100-12.

[61] Fang CL, Guan XL, Lu SS, Zhou M, Deng Y. Input-output efficiency of urban agglomeration in China: an application of data envelopment analysis (DEA). Urban Stud 2013;50(13):2766-90.

[62] Bao C, Fang CL. Geographical and environmental perspectives for the sustainable development of renewable energy in urbanizing China. Renew Sustain Energy Rev 2013;27:464-74.

[63] Wang QW, Zhou P, Shen N, Wang SS. Measuring carbon dioxide emission performance in Chinese provinces: a parametric approach. Renew Sustain Energy Rev 2013;21:324-30.

[64] Zhao YB, Wang SJ. The relationship between urbanization, economic growth and energy consumption in China: an econometric perspective analysis. Sustainability 2015;7:5609-27. 